\title{
Assessing Algebraic Solving Ability: A Theoretical Framework
}

\author{
Lim Hooi Lian ${ }^{1} \&$ Wun Thiam Yew ${ }^{1}$ \\ ${ }^{1}$ School of Educational Studies, Universiti Sains Malaysia, Penang, Malaysia \\ Correspondence: School of Educational Studies, Universiti Sains Malaysia, 11800 Penang, Malaysia. E-mail: \\ hllim@usm.my/tywun@usm.my
}

Received: July 23, 2012 Accepted: August 7, 2012 Online Published: October 12, 2012

doi:10.5539/ies.v5n6p177

URL: http://dx.doi.org/10.5539/ies.v5n6p177

\begin{abstract}
Algebraic solving ability had been discussed by many educators and researchers. There exists no definite definition for algebraic solving ability as it can be viewed from different perspectives. In this paper, the nature of algebraic solving ability in terms of algebraic processes that demonstrate the ability in solving algebraic problem is discussed. A theoretical framework of algebraic solving ability was formulated based on three phases of algebraic processes, historical development of algebra and SOLO model (Structured of the Observed Learning Outcome). The three phases of algebraic processes included investigating the pattern by collecting the numerical data, representing and generalizing the pattern into a table and an equation, and interpreting and applying the equation to the related or new situation. There are four levels (unistructural, multistructural, relational and extended abstract) of structure response of SOLO model that had been applied to assess students' algebraic solving ability incorporate two content domains of algebraic equation, namely direct variation and inverse variation.
\end{abstract}

Keywords: algebraic solving ability, algebraic equation, SOLO model, direct variation, inverse variation

\section{Introducation}

Algebraic solving ability had been discussed by many educators and researchers (Bell, 1996; Billstein, Libeskind, \& Lott, 2001; Campbell, Peterson, \& Yoshiwara, 2000; Friedlander \& Hershkowitz, 1997; Huntley, 2000; Latterell, 2003; Swafford \& Langrall, 2000). Most of their views focused on identifying the kinds of algebraic processes which are required in solving algebraic tasks or process-based (Billstein, Libeskind, \& Lott, 2001; Campbell, Peterson, \& Yoshiwara, 2000; Friedlander \& Hershkowitz, 1997; Latterell, 2003; Swafford \& Langrall, 2000). There exists no definite definition for algebraic solving ability as it can be viewed from different perspectives. A mathematician's view of algebraic solving ability is not usually the same as the view of a psychologist, an elementary school teacher or an expert on algebraic solving ability. Thus, the question of 'what is algebraic solving ability?' is not the kind of question that is readily answered by empirical research. However, we provide some perspectives of the nature of algebraic solving ability if the question is rephrased: What kinds of algebraic processes that demonstrate the ability in solving algebraic problem? Friedlander \& Hershkowitz (1997) and Swafford \& Langrall (2000) maintained that the ability of using algebraic equation to solve and represent the problem situation involves a number of algebraic processes which consist of three phases, namely: i) investigating the pattern by collecting the numerical data; ii) representing and generalizing the pattern into a table and an equation; and iii) interpreting and applying the equation to the related or new situation. These three phases of algebraic process are described in some detail below.

\section{Three phases of algebraic processes}

In the first phase, students will be presented with a series of tasks involving specific cases. The students are expected to be able to notice and recognize the pattern while working with the numerical examples (Friedlander \& Hershkowitz, 1997). According to Lee (1996), the responses of students are variety while solving this type of problem due to the different levels of algebraic solving ability and perspectives. In the second phase, students then could determine if they would be able to represent their numerical data into a table which is a commonly used form of algebraic representation (Friedlander \& Hershkowitz, 1997; Herbert \& Brown, 1997; Kaput, 1989). The representation provides a visualization of two related quantities (independent variable and dependent variable) and it can help them to find the pattern (Herbert \& Brown, 1997). According to Swafford and Langrall (2000), tables are systematic representations for a series of specific cases. It can give students a sense of the 
dynamic interaction between the variables while they represent data in table. Hence, with respect to representation, the levels of understanding of pattern among the students can be determined by teacher. Next, students are required to generalize the relationship in the problem situation symbolically using algebraic equation (Swafford \& Langrall, 2000; Friedlander \& Hershkowitz, 1997). Making generalization through some specific cases is one of the important perceptions to express generality in a problem situation. Students are probably seeing the pattern through the particular number, the particular computation and aware of generality. Friedlander and Hershkowitz (1997) and Mason (1996) noted that when students are confronted with 'unfriendly' or large number of specific example, it will push them to make a generalization for the pattern and they prompt to give the responses without having to see or draw them all. In the last phase, students could determine if and how they test the conjecture by applying the rule into the similar or new situation. In this process, students are required to interpret and apply the equation to solve the related or new problem situation in order to justify their conclusions. According to English and Warren (1995), process of testing conjecture serves to develop deductive reasoning process. It determines the valid consequence of the assumption or conjecture that the students made. Thus, testing conjecture allows for meaningful use of algebraic manipulation as part of higher algebraic solving ability.

\section{Development of Algebraic Solving Ability}

The emphasis on algebraic solving ability has raised issues such as how to introduce and develop algebraic solving ability in the classroom. A number of researchers have discussed different methods and perspectives to generate algebraic solving ability among the students.

Holbrook (1998) adapted the Wheel of Fortune television game show to introduce and develop the seventh, eighth and ninth grades students' algebraic solving ability especially in solving first-degree equation in one variable. Students found the game as exacting as the television version. They were able to solve most of the equations mentally, without using pencil and paper. This activity engaged students in solving equation by using formal and informal methods and encouraged mental computation and estimation. It also enhanced students' confidence, algebraic reasoning, algebraic solving ability and encouraged mathematical communication. The game was also an excellent opportunity to assess informally students' ability to solve algebraic problem.

Edwards (2000) experienced that in the early middle school, the most difficult aspect of developing algebraic solving ability among the students is the meaningful acquisition of algebraic notation, the concept of variable, function and properties of numbers. These four basic concepts had been highlighted as a big idea of algebra and should be developed in order to build a strong foundation of algebraic solving ability in classroom.

Smith and Philips (2000) presented student work which illustrated the range, depth and character of students' algebraic solving ability in judging about equivalence. They highlighted a few of algebraic skills which they viewed as a starter set of competencies that can served as a solid foundation for developing more advanced algebraic solving ability, these included: a) identify the quantities that vary in problem situations and describe how the variables are related; b) describe the rates of change of the relationship that was presented in table, graph or symbolic expressions; and c) understand the equivalence of algebraic expressions in multiple ways. The finding showed that the students knew different ways to think about equivalence, such as: a) substitute particular values for $x$ and compare the results; b) generate and compare tables of values; and c) simply inspect the expressions.

As far as the development of algebraic solving ability is concerned, Thornton and Stephen (2001) suggested new approach to algebra. They had highlighted three new approaches: pattern approach, symbolic approach and function approach. Each approach leaded to new insights by representing the problem situation in alternative way. Furthermore, all the approaches were sufficient because it emphasized more on conceptual understanding of variables, expressions and equations rather than symbolic manipulation.

Bishop, Otto and Lubinski (2001) identified and suggested several approaches that students used to solve algebraically about pattern. Initially, students were asked to form an arithmetic expression to solve some specific value of questions. This approach encouraged a strong connection between students' reasoning and their own representation of their reasoning (e.g., identify the recursive relationship between successive perimeters). Next, students were asked to use the previously developed strategies to build an algebraic expression (e.g., the perimeter of the $n$th shape). Lastly, students were asked to do the reverse by using linear equation (e.g., if the perimeter is 62 , how many rhombi would have?). As a conclusion, the investigation emphasis on method of counting, connect symbolic representation with their counting action and use an algebraic equation to solve the related problem. It also offers a format for implementing the algebraic process standard, including: a) students develop problem-solving strategies for finding perimeter; b) students communicate their strategies in words and 
symbols; c) students reason about the relationship between counting strategies and symbolic representations; and d) students connect the counting method of arithmetic with the generalization of algebra.

However, Ferrucci, Yeap and Carter (2003) discussed about the modeling approach in enhancing algebraic solving ability. They found that modeling approach was a powerful tool for middle school students in Singapore to enhance their problem solving skill. This approach was intended to help students to visualize abstract mathematics relationship in the models that helped them to better comprehend symbols and manipulations of algebraic equations.

Meyer (1999) viewed that if the routine manipulations problems were presented to the students, normally the teachers can anticipate the ways in which students would respond and it was easy to tell whether the students know how to do the problem and whether she or he got the right answer. Moreover, the mistakes that students might make on this type of problem were predictable and thus few judgments needed to be made because the strategy was either appropriate or not; and barring computational errors, the answer was either right or wrong. Meyer suggested that students must have experience with a wide variety of problem solving methods and opportunities for solving a wide range of problems. Thus, several challenges should be practiced in developing the students' algebraic solving ability. These include: i) creating a classroom atmosphere in which multiple strategies are possible; ii) recognize the different mathematical understanding revealed by the different solution strategies; iii) encourage the students to share different ways of problem solving; iv) push the student to make the next leap in understanding the strategies that she or he is closing to use it; and v) understanding their different strategies by modeling how they evaluate conjectures.

Consistent with Meyer's view, Femiano (2003) shared his teaching experiences that problem solving and pictorial representation were more practical ways to promote algebraic solving ability amongst the primary-grade students. Once equations were transformed into concrete problems, the students can make sense of the problems. They were able to understand easily the role of an unknown and this conceptual understanding allowed them to logically generate a solution plan that was based on reasoning rather than on memorized methods.

Fernandez and Anhalt (2001) presented some mathematics tasks used to help students to expand their views of algebra, as well as the importance of engaging students in algebraic problem solving and exploration of mathematical ideas through a variety of representation. Thus, a transition Toward Algebra project had been developed to promote a rich and positive environment in expanding Grade Five to Grade Nine students' view of algebra. This project presented three views of algebra: i) as the study of patterns and relationships; to emphasize on numerical pattern and visual model. For instance, represent the data collected into a table to look for pattern and relationship; ii) as a tool for problem solving; to understand the relationship among the variables and using graph and table to make conjecture of the solution; and iii) as generalized arithmetic; to realize the exploration and generalization of relationship for numerical operation. All the three views had been described and presented through a variety of algebraic problems. They found that this project was having a positive influence on teachers' and students' knowledge and practices. It had also helped the students to understand the importance of engaging in problem solving, discovering relationship and translating among representation.

A more sophisticated approach seems to lie in Sinclair's study. According to Sinclair (2005), the use of spreadsheet to solve algebraic problems was able to help students visualize mathematical concepts, to permit more realistic problems to be tackled, to allow students to analyze a situation using multiple representations and use computer in later mathematics courses. Three results stood out through the use of spreadsheets in developing algebraic solving ability. These included: i) students employe a wide variety of solutions when they were not limited by problem type; ii) they displayed considerable skill in creating and manipulating formulas; and iii) they approached new and different problems with confidence.

Nevertheless, some researchers claimed that the historical analysis of algebra do reflect the development of algebraic solving ability. They stated that the ability to generalize arithmetic properties is often the lifeblood of algebra. Hence, the emphasis on arithmetic is important to build a good foundation of algebraic solving ability and it will lead them to be able to apply it in daily life especially problem solving by using equation.

\section{Historical development of algebra}

Sfard and Linchevski (1994) found that the historical development of algebra highlights the distinction between using letter to represent unknown in equation and using letter to represent in expressing general solutions.

According to Sfard (1995), there are several stages of development to algebra on historical analysis. In the earliest stage, which is called rhetorical stage, it was characterized by the use of ordinary language description and concrete number to present the solution in finding the unknown. The focus is definitely on numerical process. 
Later, the rhetorical algebra was practiced from the combination of word and symbols. It was initiated by Diophantus who introduced the use of letters for unknown quantities. Then, the innovative use of letter to stand for the given was elaborated by Viete (1540-1603). In second stage, the development of concept variable in the structural phase - a notation that was elaborated by Viete, Leibniz (1646-1716), and Newton (1642-1727). In this stage, the use of algebra as a tool for proving rules governing numerical relations. This invention was also led to the reaching of conceptual change in algebra. In the crucial stage, algebra with some new processes had been introduced. The early concept of function which was involved with numerical operations serve as inputs was soon replaced by more structural conceptions. The processes express in manipulations on algebra formula.

The historical analysis above allows us to view the development of algebra through the centuries that also reflects the cognitive development of algebraic solving ability in individual. It is seen as a cycle of procedural-structural evolution and also in a hierarchical structures in which what is conceived operationally (procedurally) at one level must be perceived structurally at a higher level. In other words, we can say that the operational conception emerges first and that the structural conception develops afterward. According to Sfard (1995), operational conception (procedurally) refers to arithmetic operations carried out on numbers to yield number. Meanwhile structural conception refers to a different set of operations that are carried out not on numbers but on algebraic expressions. For instance, write an equation using the variables to represent the situation. Thus, the cognitive development in algebraic solving ability is focused on these two transition which are in hierarchical structure, namely from the purely operational algebra to the structural algebra of a fixed value (of an unknown) and then from here to the functional algebra (of variable) and abstract algebra.

Obviously, based on the research findings and historical development of algebra, the series of algebraic solving processes represent the various stages. That is, initially are solved numerically and later the application of algebraic method. In this study, the three phases identified by Friedlander and Hershkowitz (1997), Swafford and Langrall (2000), and Sfard (1995) had been adapted to assess the students' algebraic solving ability across two content domains of algebraic equation which are based on the mathematics syllabus of the Integrated Curriculum for Secondary School or Kurikulum Bersepadu Sekolah Menengah (KBSM) (Ministry of Education, 2000). These include direct variation and inverse variation. Both content domains are described below.

\subsection{Direct Variation}

In mathematical definition, direct variation is a situation when two variables are related in such a way that the ratio of their values always remains the same. In other words, direct variation means two variables quantities have a constant ratio. It is said that one quantity is directly proportional to another when the ratio of the two quantities is constant. Direct variation is described by an equation of the form $y=k x$ where $x$ and $y$ are the related objects and $k$ is called the constant of variation. Student's cognitive ability in direct variation tasks has been studied (e.g., Swafford \& Langrall, 2000; Lee, 2003). Swafford and Langrall stated that although majority of $6^{\text {th }}$ grade students were often able to write equation to represent the direct variation situation but they tended to use mental mathematics strategies to solve the problem. Lee (2003) gave a compelling explanation of this problem. He claimed that when students were presented with the direct variation equation, they encountered the problem to use the given values and inverse operation to find the unknown quantity.

In formulating the levels of the framework with respect to direct variation, the findings of these studies had been recognized by establishing algebraic solving ability expectations involving with representation and application of direct variation equation.

\subsection{Inverse Variation}

An inverse variation is a situation in which one quantity increases while another quantity decreases, such as speed and travel time for a given distance. The product of the quantities remains constant; that is, as one quantity doubles, the other quantity is cut in half (Lee, 2003; The Annenberg/CPB, 2005). In mathematical definition, inverse variation means the ratio of one variable to the reciprocal of the other is constant. It means that when one variable increases, the other variable decreases in proportion so that the product is unchanged (The Annenberg/ $\mathrm{CPB}, 2005)$. Inverse variation is described by an equation of the form $y=k / x$ where $y$ varies inversely with $x$ and $y$ is proportional to $k$, which is a constant. Swafford and Langrall (2000) noted that inverse variation situation is the most difficult for students due to the lack of understanding about the concept of inverse variation. It was suggested that students need more exploration with this situation before studying them analytically in algebraic. Thus, in this study, the inverse variation tasks represent the various stages. That is, initially the ability to solve the numerical examples and later the ability to use the algebraic method. In other words, they should be able to find the answers by performing numerical operation on given values of the independent variable before applying the algebraic symbol to represent the situation. 


\subsection{Assessment in Algebra}

As the conceptual understanding is deemed to be an important factor in the empowerment of meaningful algebra learning, significant progress had been made in charting the role of assessment in generating algebraic solving ability through the application of algebraic concepts in the real life problem situation amongst the students. A number of researchers had highlighted some failures in the assessment which without really confronting students with algebraic solving ability. For example, Stacey and MacGregor (1999) investigated the implication of the new curriculum policy on algebra learning in year 7 to 11 . They reported that most of the problems solving items were still too simple to solve (only simple numbers are used in the algebra problems). It can be solved easily without any algebra, either by logical reasoning or trial and error and thus students faced difficulties in coping with other arithmetic concepts such as decimal, fractions, negative quantities, equivalence, ratio, percentage, ratio or exponential.

Clements (1999) claimed that the stereotype of algebra classes in Brunei remained the same. The development of algebraic solving ability was being sidelined in many schools where the students' aim was simply to get right answer and the teachers' aim was to channel students to be able to apply a fixed routine to solve the problem which enable them to get right answer. According to Clements, it is deemed necessary to make changes of assessment to ensure that teachers and students are able to develop more active, more holistic and more contemporary, approaches to algebra.

Fortunately, cognitive psychology has provided insight into the assessment of cognitive ability and learning pointing the way to new approaches to classroom. The SOLO taxonomy, known as the Structure of the Observed Learning Outcome, was developed by Biggs and Collis (1982). It is a cognitive psychology model which emphasizes more on the internal process and more interested in investigating how a problem is handled by students rather than whether their answers are correct.

\section{SOLO Model}

SOLO model is designed mainly as a mean to assess students' learning outcome. The SOLO taxonomy focuses on the structure of an individual's response, to describe the quality of learning. SOLO provides a framework to classify the quality of response which can be inferred from the structure of the answer to a stimulus. According to SOLO model, coding a student's response depends on two features. The first is a series of five modes of cognitive development and the second is a series of levels of response. These two features clearly form the basis for the theoretical stance taken by Biggs and Collis (1982) in the SOLO model which is described in some detail below.

\subsection{Mode of Cognitive Development}

In SOLO model, mode is closely related to the existing notion of Piaget's stage of cognitive development which proposes a number of developmental stages demonstrating increasing abstraction from sensori-motor (infancy), ikonic (early childhood of preschool), concrete-symbolic (childhood to adolescene), formal (early adulthood) through postformal (adulthood) (Biggs \& Collis, 1982; Biggs \& Collis, 1989; Biggs \& Teller, 1987; Collis \& Romberg, 1986; Romberg, Zarinnia, \& Collis, 1990).

i. Sensori-motor: It is the mode which is associated with the performance of skilled motor activities. For instance, a person reacts to the physical environment and gives a motor response to a sensory stimulus.

ii. Ikonic: It is the mode that the person develops words and images which represents objects and events. For instance, a person internalizes actions in the form of image.

iii. Concrete-symbolic: This is the most common mode addressed in the upper primary and secondary school systems (Biggs \& Collis, 1989). For instance, a person thinks through using a symbol system such as written language and number system.

iv. Formal: This mode can be described as working in terms of 'principles' and 'theories'. A person considers more abstract concepts than in concrete-symbolic mode. For instance, a person begins to question how things are and form hypotheses about how things might be instead of accepting them.

v. Post formal: A person is able to question or challenge the fundamental principles or theories.

Although the sequence of five modes followed from simple to complex, it is common knowledge that students do not always operate at the same level as their developmental age suggests they should nor do they perform consistently (Biggs \& Collis, 1982; Biggs \& Teller, 1987; Collis \& Romberg, 1986; Romberg, Zarinnia, \& Collis, 1990). For example, a formal mode response in Chemistry given by a student might be followed by a series of concrete-symbolic mode response in Biology. Furthermore, concrete-symbolic mode response in Economic 
given by a student on this month might be followed by formal mode response on the next month. Was that particular student at the formal mode or concrete-symbolic mode? According to SOLO model, this kind of difficulty can be solved by shifting the label from the student to his response to a particular task (Biggs \& Collis, 1982). In other words, SOLO model improves this phenomenon by describing the complexity of the structure response to a particular task within a mode which is described in more detail below.

\subsection{Structure Response}

SOLO model found that when students answer the tasks given, their responses to the task can be summarized in terms of five levels (Biggs \& Collis, 1982; Biggs \& Collis, 1989; Chick, 1988; Chick, 1998; Wilson \& Iventosch, 1988; Wongyai \& Kamol, 2004; Wilson \& Chavarria, 1993), ranging from prestructural to extended abstract, which are described below.

The taxonomy consists of five levels of response structure as follows:

i. Prestructural - responses show that the understanding of the question point is inappropriately.

ii. Unistructural - responses represent the use of only one relevant aspect of the information in the question.

iii. Multistructural - responses focus on several relevant aspects of information given but there are treated independently, additively or sequentially.

iv. Relational - responses integrate all relevant pieces of information to make a generalization or to form a structure.

v. Extended abstract - responses apply the structure into a new and more abstract situation. This may allow generalization to a new topic or area.

The five levels of structure responses above represented both an increase in the use of the relevant information and an increase in the complexity of structure response. In the level of unistructural and multistructural, responses may only involve one or more relevant given information in the task and thus there is little relationship between the task and the given information. Further, in these levels, a student needs only encode the given information and use directly to give response. Otherwise, at the relational or extended abstract, the student needs to form a structure within the given information and an abstract principle, concept or theory which is not given directly in the task. Besides, at the relational or extended abstract level, the student needs to understand the task in a way that is personally meaningful and links up with the existing knowledge.

\subsection{Research Related to the Using of SOLO Model in Assessing Cognitive Development}

From the literature on the SOLO taxonomy, it was suggested that SOLO is a hierarchical model that is suitable for measuring learning outcome of different subjects as follow.

\subsubsection{Science}

A study done by Lake (1999) outlined an adaptation of SOLO model that provides student and teacher with a pedagogically sound template which can be used to develop critical numerical skill especially interpretation of graph and table in learning of biology. In this context, SOLO model is visualized as a spiral learning structure repeating itself with increasing levels of abstraction; each level built on the skill that was acquired at the previous one. Thus, it was useful to be designed to classify the problem solving processes by stages (unistructural, multistructural, relational and extended abstract) and adapted to provide a useful four-step template of generalized questions that leaded students from the basic skills to critical analysis.

Levins (1997) attempted to show that how SOLO model was appropriate to categorize the students' written responses into the cognitive classification framework for similar or different ages, which these existed at different degrees of consistency of particular ideas about certain scientific concepts. In this study, three questions were given to 190 students from years 7-12. Two cycles reflected an increase in the students' power of abstraction from the first to the second cycle. The first cycle was one in which the students acquired basic skills and concepts. For instance, they suggested some features such as steam, water, heat and gas which were the descriptions concerning evaporation. In other words, they reacted to reality as they saw it. In the second cycle, the students were able to conceptualize the ideas they possessed concerning their ideas of evaporation. Thus, this study provided an analysis of the growth of the evaporation concept within the theoretical framework of the SOLO model. This model enclosed the growth of basic understanding about the concepts must have in place before the transition to the more demanding abstract ideas.

\subsubsection{Counseling}

Burnett (1999) presented that SOLO model provides an existing way to view the quality of learning outcomes of 
counseling within a learning framework. The clients' written responses were analyzed and classified by using this model. In the exploratory study, the clients were asked to write a letter to a friend describing as much detail as possible what they had learned and how they gained or benefited from counseling. The result obtained from this study revealed that majority of the clients fall within the multistructural category based on the classification of SOLO level. It means that most of the clients were not integrating the knowledge learned in the counseling context. The aspects learned were still treated as unrelated. This approach may have implication for the process of counseling because counselors can use this technique to enhance their clients' learning.

\subsubsection{Practice Subject}

An attempt on applying SOLO model in a practice subject was done by Chan, Tsui, and Chan (2002). The scripts of long essay papers and short classroom discussion responses from postgraduate students who had taken an advanced practice subject in mental health were analyzed using SOLO model. In the finding, it was found that SOLO was suitable for measuring the work in content variation of practice subjects and it could be applied to the students who were from different levels of cognitive learning outcome. They discovered that the classification of levels that sub-levels were added to SOLO model that would reduce the ambiguity and increase agreement between rater (inter-rater reliability). For instance, presturctural, unistructural, multisturctural moderate level, multistructural high level, relational moderate level, relational high level and extended abstract level.

\subsubsection{Mathematics}

SOLO model had been used in assessing students' cognitive attainment in several mathematics areas and skills, including statistics, algebra, probability, geometry, error analysis and problem solving.

\section{a. Statistics}

Mooney (2002) attempted to build an integrated picture of students' thinking that incorporates four key statistical processes. The SOLO model framework had been developed in characterizing the development of middle school students' thinking across four processes, namely describing data, organizing and reducing data, representing data and analyzing and interpreting data. The profile showed a strong internal consistency in students' statistical thinking across the four processes. Mooney (2002) found that 5/12 of the students achieved the same level of thinking for any three out of the four statistical processes. Based on this model, it can be concluded that the four statistical processes closely linked although examined separately.

Similarly, Reading (1999) used SOLO model to classify 180 students' responses (academic years 7 to 12) concerning the statistical understanding in data tabulation and representation.They were allowed to respond as much information as he or she felt was necessary. Three major grouping of the levels were identified based on the depth to which the responses indicated the ability of the student to understand the representation of the data. The first group dealt with only the requirement of the question. The second group was concerned with attempting to understand the data. The third group of responses indicated a readiness to describe the information contained in the data in a more acceptable form. Also, there was an increase in level with academic year. Younger students were more likely to use judgments in their descriptions while older students were more likely to use statistics.

Vallecillos and Moreno (2002) described that SOLO model can be used as a framework to characterize and assess the learning of elementary statistical inference amongst 49 secondary students aged 14-15 years old and 17-18 years old. Two different parts with 12 items each were constructed in three different contexts, namely concrete, narrative and numeric. Four constructs had been established, namely: i) population and samples and the relationship; ii) inferential process; iii) sample sizes; and iv) sampling types and biases. The researchers described three levels of observed learning outcomes (unistructural, multistructural and relational) for each construct. The findings demonstrated that the higher age students performed better than lower age students especially in two of the constructs, namely: i) populations and samples and their relationship; and ii) sample size.

In Aoyama's study (2007), SOLO model was used to investigate the hierarchy of interpretations of graphs among 175 students from different education levels in Japan (junior high school to graduate students). All participants completed a questionnaire including three or four items each based on a different theme, and having three to five questions asking about the interpretation of a graph and its context. Rasch model was used to clarify the construction of hierarchy. Five different levels of interpretations of graphs were identified, namely idiosyncratic, basic graph reading, rational/literal, critical and hypothesizing and modeling. Generally the students' performance progressed with age, but the performance of junior college students was slightly lower than those of high school students. The hierarchy of interpretations of graphs was found to be very useful in preparing further guidelines for teaching statistical literacy. In this context, SOLO model was applied to measure the learning 
outcome of students who were in different academic year. It can therefore be seen that age influenced the thinking ability in statistics. The degree of abstraction that was utilized by the learner in handling the element of the tasks closely related to the stages of development.

b. Geometry

Serow (2007) integrated SOLO model and Rasch model to gain insight into students' understanding of class inclusion concepts in geometry. The partial credit analysis was used to provide data concerning the distances between response categories and clusters of response categories. The qualitative study involved in-depth interviews with 24 students of higher mathematical ability, purposely selected, within Years 8-12 (ages 13-18 years) in two secondary schools. In the tasks concerning relationships among figures, and those concerning relationships among properties, a hierarchical framework emerged that is evident in the SOLO categorisations and is reinforced by the application of the Rasch analysis. Each of the items followed the SOLO sequence of levels within cycles without exception. The step difficulty between a U2(CS) response and an M2(CS) response concerning relationships among figures has a mean of 0.64 . It was also found to be difficult by the sample of students to respond at R2(CS) compared with M2(CS) concerning relationships among figures (mean 1.18). This was similar to the step difficulties concerning relationships among properties, where M2(CS) to R2(CS) (mean 0.70 ) was found to have a comparatively high step difficulty.

\section{c. Probability}

Jones et al. (1997) had applied SOLO model to formulate a framework for assessing 15 middle school students' thinking in conditional probability and independence. The structured interview protocol (14 tasks) was used to collect the students' responses. A double-coding procedure then was used to identify the level based on the descriptors in the framework. The framework then was validated through data obtained from eight grade three children who served as case studies. The results suggested that although the framework produced a coherent picture of students' probability thinking, there was 'static' in the system which generated inconsistencies within levels. The levels of thinking appeared to be in agreement with level of cognitive development based on SOLO model and provided a theoretical foundation for designers of curriculum and assessment program in elementary school probability.

\section{d. Error analysis}

Chick, Watson, and Collis (1988) presented that how the extended SOLO Taxonomy can be applied in analyzing error in a variety of mathematics topics. In order to illustrate the SOLO levels, task analysis maps were devised by Chick (1988) to describe the types of errors being made by students in solving the mathematics problems. It was used to accomplish whether students had been successful in attaining the level of solutions desired. According to Chick, a correct solution would not be obtained if the solver was operating at unsatisfactory levels in any one of the necessary concepts areas. Thus, it was interesting to determine the areas in which the difficulties lie based on the pictorial nature of the task analysis and response maps. This method is useful for teachers in analyzing students' mistakes, showing the potential for facilitating the comparison of students' solution with 'ideal' or correct solution, identifying the conceptual difficulties and misconceptions, and examining the way of students in using the information given in the problem.

\section{e. Algebra}

Pegg (2001) used SOLO model to describe the development of algebraic knowledge and thinking ability. In this study, SOLO model comprised a recurring cycle of three levels referred to as unistructural, multistrustural, and relational. Two algebraic examples were presented in which one of the item had been applied to a number of secondary classes in 2001 and another one had been used initially by Biggs in 1982. Based on the students' responses, SOLO model was used to classify algebraic solving ability in UMR (unistructural, multistructural, relational) cycle in the concrete symbolic second cycle mode which is closely to formal one mode.

In this study, SOLO model was used in reverse and combining it with the idea of superitem. That is, within any superitem, a correct response to a question would indicate the cognitive ability at the certain level reflected in the SOLO structure of that question. The criteria used to write the four level questions are as follow (Collis, Romberg, \& Jurnak, 1986):

i. Unistructural - one obvious piece of information was used. The information was obtainable directly from the stem (the story or problem situation).

ii. Multistructural - all the necessary pieces of information was used in a sequence but do not integrate them. The information given may use as a recipe where a set of instructions are followed to solve the problem. 
iii. Relational - the given information is insufficient to solve the problem immediately. Alternatively, the information must be carefully inter-related to produce a satisfactory solution or to form a structure.

iv. Extended Abstract - a response that use of an abstract general principle or hypothesis derived from or suggested by the information in the stem to a new and more abstract situation.

There are four levels of structure response that had been applied to construct four levels questions in a superitem about algebraic equation. The correct achievement of the first question (first level: unistructural) in the superitem would indicate that the algebraic solving ability at least the unistructural level.

\section{Theoretical Framework}

Table 1. The framework on the characteristics of students' algebraic solving ability incorporate direct variation and inverse variation

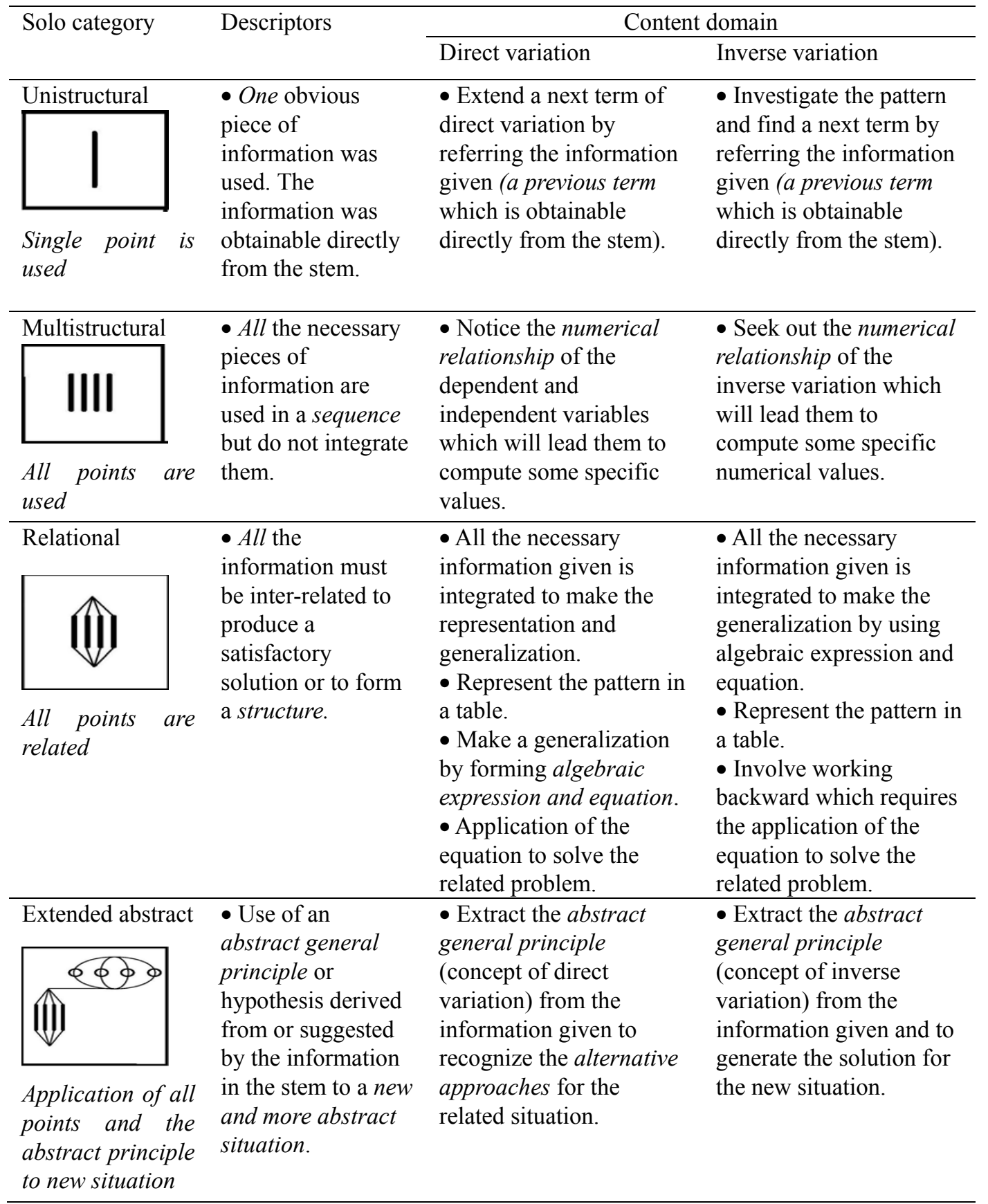


Since the study focuses on secondary students, we hypothesized that the students are on the concrete-symbolic mode of SOLO model. The concrete-symbolic mode involves a more abstract process of learning and is considered as a significant shift in abstraction, from direct symbol systems of the world through oral language, to the use of second order symbol systems such as written language signs and mathematical symbol system (Romberg \& Collis, 1991; Wongyai \& Kamol, 2004). For instance, students can master the concept of algebraic function. He can let ' $x$ ' be 'any number'. Whereas the iconic mode, student has had no experience of 'any number', but only had experience of 'particular number' (Biggs \& Collis, 1982). According to Biggs and Collis (1989), mastery of symbol system and application of them to real world problem is the major task in primary and secondary schooling according to any curriculum. We hypothesized that Form Four (Grade 10) students could exhibit four levels of algebraic solving ability based on SOLO model, namely unistructural, multistructural, relational and extended abstract. The theoretical framework had been developed along with the expected students' algebraic solving ability across the four levels for each of the content domains. Table 1 shows the framework on the characteristics of students' algebraic solving ability incorporate two content domains of algebraic equation. The diagram shows the structure of response for each level (Biggs, 2003).

\section{Conclusion}

The framework generated enables the students' algebraic solving ability to be described in a coherent and systematic manner. Notwithstanding the extent of research into students' algebraic solving ability, recent research has not investigated the both content domains in combination (Wongyai \& Kamoi, 2004). Accordingly, the literature does not provide the kind of coherent picture of students' algebraic solving ability that is desirable for current approaches to assessment and instruction.

\section{Acknowledgements}

This paper was made possible with funding from the Short Term Grant of University Sains Malaysia, Penang, Malaysia.

\section{References}

Aoyama, K. (2007). Investigating a hierarchy of pre-service teachers' interpretation of graphs. International Electronic Journal of Mathematics Education, 2(3), 298-318.

Bell, A. (1996). Problem solving approached to algebra: Two aspects. In N. Bednarz, C. Kieran, \& L. Lee (Eds.), Approaches to algebra: Perspectives for research and teaching (pp. 167-186). Dordrecht: Kluwer.

Biggs, J. B. (2003). Teaching for quality learning at university (2nd ed.). Buckingham: SRHE and Open University Press.

Biggs, J. B., \& Collis, K. F. (1982). Evaluating the quality of learning: The SOLO taxonomy (Structure of the Observed Learning Outcome). New York: Academic Press.

Biggs, J. B., \& Collis, K.F. (1989). Towards a model of school-based curriculum development and assessment using the SOLO taxonomy. Australians Journal of Education, 33(2), 151-163.

Biggs, J. B., \& Teller, R. (1987). The process of learning (2nd ed.). Hobart, USA: Academic Press.

Billstein, R., Libeskind, K., \& Lott, J. W. (2001). A problem approach to mathematics for elementary school teacher (7th ed.). Boston: Addison Wesley Longman.

Bishop, J. W., Otto, A. D., \& Lubinski, C. A. (2001). Promoting algebraic reasoning using students' thinking. Mathematics Teaching in the Middle School, 6(9), 508-514.

Burnett, P. C. (1999). Assessing the structure of learning outcome from counseling using the SOLO Taxonomy: An exploratory study. British Journal of Guidance \& Counseling, 27(1), 567-580.

Campbell, R. D., Peterson, J. C., \& Yoshiwara, K. (2000). Information Technology, 1. Retrieved May 1, 2005, from CRAFTY Curriculum Foundations Project Web site: http://www.waketech.edu/ rlkimbal/CRAFTY/reportinf.doc.

Chan, C. C., Tsui, M. S., \& Chan, M. Y. C. (2002). Applying the Structure of the Observed Learning Outcomes ( SOLO) Taxonomy on student's learning outcomes: An empirical study. Assessment and Evaluation in Higher Education, 27(6), 511-528. http://dx.doi.org/10.1080/0260293022000020282

Chick, H. L. (1988). Student responses to polynomial problem in the light of the SOLO taxonomy. Australian Senior Mathematics Journal, 2(2), 91-110.

Chick, H. L. (1998). Cognition in the formal modes: Research mathematics and the SOLO Taxonomy. 
Mathematics Education Research Journal, 10(2), 4-26. http://dx.doi.org/10.1007/BF03217340

Chick, H. L., Watson, J. M., \& Collis, K. F. (1988). Using the SOLO Taxonomy for error analysis in mathematics. Research in Mathematics Education in Australia, May-June, 34-36.

Clements, M. A. (1999). The teaching and learning of algebra. Proceedings of the First Brunei Mathematics Teacher Conference, Negara Brunei, 31-46.

Collis, K. F., Romberg, T. A., \& Jurdak, M. E. (1986). A technique for assessing mathematical problem-solving ability. Journal for Research in Mathematics Education, 17(3), 206-221. http://dx.doi.org/10.2307/749302

Edwards, T. G. (2000). Some big ideas of algebra in the middle grades. Mathematics Teaching in the Middle School, 6(1), 26-32.

English, L. D., \& Warren, E. A. (1995). General reasoning processes and elementary algebraic understanding: Implications for initial instruction. Focus in Learning Problems in Mathematics, 17(4), 1-19.

Femiano, R. B. (2003). Algebraic problem solving in the primary grades. Teaching Children Mathematics, 9(8), 444-449.

Fernandez, M. L., \& Anhalt, C. O. (2001). Transition toward algebra. Mathematics Teaching in the Middle School, 7(4), 236-242.

Ferrucci, B. J., Yeap, B. H., \& Carter, J. A. (2003). A modeling approach for enhancing problem solving in the middle grades. Mathematics Teaching in the Middle School, 8(9), 470-476.

Friedlander, A., \& Hershkowitz, R. (1997). Reasoning with algebra. The Mathematics Teacher, 90(6), 442-447.

Herbert, K., \& Brown, R. H. (1997). Patterns as tools for algebraic reasoning. Teaching Children Mathematics, 3(6), 340-345.

Holbrook, E. L. (1998). Wheel of fortune for the mathematic classroom. Mathematics Teaching in the Middle School, 4(1), 32.

Huntley, M. A. (2000). Effects of standards-based mathematics education: A study of the Core-Plu Mathematics Project Algebra and Function Strand. Journal for Research in Mathematics Education, 31(3), 328-362. http://dx.doi.org/10.2307/749810

Jones, G. A., Langrall, C. W., Thornton, C. A., \& Mogill, A. T. (1997). A framework for assessing and nurturing young children thinking in probability. Educational Studies in Mathematics, 32, 101-125. http://dx.doi.org/10.1023/A:1002981520728

Kaput, J. J. (1989). Supporting concrete visual thinking in multiplicative reasoning: Difficulties and opportunities. Focus on Learning Problems in Mathematics, 11(1), 35-60.

Lake, D. (1999). Helping students to go SOLO: Teaching critical numeracy in the biological science, Journal of Biological Education, 33(4), 191-199. http://dx.doi.org/10.1080/00219266.1999.9655664

Latterell, C. M. (2003). Testing the problem solving skills of students in an NCTM-oriented curriculum. The Mathematics Educator, 13(1), 5-14.

Lee, L. (1996). An initiation into algebraic culture through generalization activities. In N. Bednarz, C. Kieran, \& L. Lee (Eds.), Approached to algebra: Perspective for research and teaching (pp. 87-106). Dordrecht: Kluwer.

Lee, R. E. (2003). The triangle technique for solving direct variation problems. Mathematics Teacher, 96(6), 450-451.

Levins, L. (1997). Assessment of students outcome using a theoretical framework. Australian Science Teachers' Journal, 43(1), 56-60.

Mason, J. (1996). Expressing generality and roots of algebra. In N. Bednarz, C. Kieran, \& L. Lee (Eds.), Approaches to algebra: Perspectives for research and teaching (pp. 65-86). Dordrecht: Kluwer.

Meyer, M. R. (1999). Multiple strategies = multiple challenges. Mathematics Teaching inthe Middle School, 4(8), 519.

Ministry of Education. (2000). Kurikulum Bersepadu Sekolah Menengah: Huraian Sukatan Matematik Tingkatan Empat. Kuala Lumpur: Pusat Perkembangan Kurikulum.

Mooney, E. S. (2002). A framework for characterizing middle school students' statistical thinking. Mathematical Thinking and Learning, 4(1), 23-64. http://dx.doi.org/10.1207/S15327833MTL0401_2 
Pegg, J. (2001). Fundamental cycles in learning algebra. Retrieved September 7, 2003, from University of New England, Center for Cognition Research in Learning and Research Web site: http://www.edfac.unimelb.edu.au

Reading, C. (1999). Understanding data tabulation and representation. Retrieved October 1, 2003, from University of New England, Armidale, Centre for Cognition Research in Learning and Research Web site: http://fehps.une.edu.au./f/s/curric/c Reading/.

Romberg, T. A. (1992). Assessing mathematics competence and achievement. In H. Berlak, F. M. Newmann, E. Adams, D. A. Archbald, T. Burgess, J. Raven, et al., Toward new science of educational testing and assessment (pp. 23-52). New York: State University of New York.

Romberg, T. A., Zarinnia, E. A., \& Collis, K. F. (1990). A new world view of assessment in mathematics. In G. Kulm (Ed.), Assessing higher order thinking in mathematics (pp. 21-38). Washington: America Association for the Advancement of Science.

Serow, P. (2007). Utilising the Rasch model to gain insight into students' understandings of class inclusion concepts in geometry. In J. Watson, \& K. Beswick (Eds.), Mathematics: Essential Research, Essential Practice - Volume 2 (Proceedings of the 30th annual conference of the Mathematics Education Research Group of Australasia, pp. 651-66). MERGA Inc.

Sfard, A. (1995). The development of algebra: Confronting historical and psychological perspectives. Journal of Mathematical Behavior, 14(1), 15-40. http://dx.doi.org/10.1016/0732-3123(95)90022-5

Sfard, A., \& Linchevski, L. (1994). The gains and the pitfalls of reinfication - the case of algebra. Educational Studies in Mathematics, 26, 191-228. http://dx.doi.org/10.1007/BF01273663

Sinclair, F. (2005). Algebraic problem using spreadsheets: A unit for grade 9. Retrieved March 1, 2005, from http://mathforum.org/workshops/sum98/participants/Sinclair/problem/intro.htm/.

Smith, J., \& Phillips, E. (2000). Listening to middle school students' algebraic thinking. Mathematics Teaching in the Middle School, 6(3), 156-161.

Stacey, K. (1989). Finding and using patterns in linear generating problems. Educational Studies in Mathematics, 42(3), 379-402.

Stacey, K., \& MacGregor, M. (1999). Implications for mathematics education policy of research on algebra learning. Australian Journal of Education, 43(1), 58-71.

Swafford, J. O., \& Langrall, C. W. (2000). Grade 6 students' preinstructional use of equation to describe the represent problem. Journal for Research in Mathematics Education, 31(1), 89-112. http://dx.doi.org/10.2307/749821

The Annenberg/CPB. (2005). Insights into algebra: Teaching and learning. Retrieved March 1, 2005, from http://www.learner.org/channel/workshops/algebra/workshop7/

Vallecillos, A., \& Moreno, A. (2002). Framework for instruction and assessment on elementary inferential satistics thinking. Proceedings of the Second International Conference on the Teaching of Mathematics, Greece, 1-9.

Wilson, L.D., \& Chavarria, S. (1993). Superitem test as a classroom assessment tool. In N. L. Webb, \& F. A. Arthur (Eds.). Assessment in the mathematics classroom (pp. 135-142). Virginia: NCTM.

Wilson, M., \& Iventosch, L. (1988). Using the partial credit model to investigate responses to structured subtest. Applied Measurement in Education, 1(4), 319-334. http://dx.doi.org/10.1207/s15324818ame0104_4

Wongyai, P., \& Kamol, N. (2004). A framework in characterizing lower secondary school students' algebraic thinking. Retrieved December 23, 2004, from http://www.icme-organisers.dk/tsg09/PiyavadeeWongyai.pdf 